\title{
Correction to: Implementing Coordinated Specialty Care in CMHC Youth and Young Adults with Severe Mental Illness: Preliminary Outcome Assessment
}

\author{
Joshua Ray Tanzer ${ }^{1}$ (1) . Colleen A. Redding ${ }^{1}$ - Irena Mikhalyuk ${ }^{1} \cdot$ Bridget Bennett $^{2} \cdot$ Barbara Lamoureux $^{3}$. \\ Denise Achin ${ }^{4} \cdot$ Shayna Bassett $^{1} \cdot$ Rosemarie Martin $^{5} \cdot$ L. A. R. Stein ${ }^{1,4,5,6}$
}

Published online: 1 February 2021

(c) Springer Science+Business Media, LLC, part of Springer Nature 2021

\section{Correction to: Community Mental Health Journal} https://doi.org/10.1007/s10597-020-00763-9

The original version of this article unfortunately missed to include the funding information.

The complete funding section is given here:

Funding These data were collected with assistance from a grant from the Substance Abuse \& Mental Health Services Administration, grant number SM061885.

The original article has been corrected.
Publisher's Note Springer Nature remains neutral with regard to jurisdictional claims in published maps and institutional affiliations.

The original article can be found online at https://doi.org/10.1007/ s10597-020-00763-9.

Joshua Ray Tanzer

joshua_tanzer@uri.edu

1 Psychology Department, University of Rhode Island, 142

Flagg Road, Kingston, RI 02881, USA

2 Community Care Alliance, Woonsocket, USA

3 Thrive Behavioral Healthcare, Warwick, USA

4 Rhode Island Department of Behavioral Healthcare,

Developmental Disabilities and Hospitals, Cranston, USA

5 Brown University School of Public Health, Providence, USA

6 RI Training School, Cranston, USA 